Acta Poetica 28 (1-2)

PRIMAVERA-OTOÑO

2007

\title{
Narrar la imagen. The Pillow Book
}

\author{
Sara Sutton
}

El libro de la almohada, de Sei Shonagon, escrito en el siglo x, es el texto que inspira a Peter Grenaway para filmar The Pillow Book. Sin embargo, la escritura de El libro de la almohada se dice diferente desde la mirada lúdica de la lente. Nagiko, personaje principal del filme, es una ferviente lectora de El libro de la almohada que encuentra en la escritura algo más que un recurso literario. Marcada por el trazo que su amado padre pintaba sobre su rostro cada cumpleaños, se aboca a buscar, desde la muerte de éste, al hombre ideal: aquel que será un sublime amante y a la vez un excelso calígrafo que entinte su piel. Pero la historia es lo menos importante, pues aquí, el lenguaje cinematográfico aparece como otra forma de escriturar, otro modo de decir que no se subyuga a la lógica de un texto alfabético, sino que transforma la letra en imagen: no son sólo palabras que narran una historia, sino imágenes que cobran sentido en el entretejido de una escena.

The Pillow Book of Sei Shonagon, written in the $10^{\text {th }}$ century, is the text that inspires Peter Greenaway to film The Pillow Book. Nevertheless, the text of the book appears differently through the lens of the camera. Nagiko, the principal character of the film, is a passionate reader of The Pillow Book of Sei Shonagon who discovers that writing could not be reduced to a literary resource. After the death of her beloved father, governed by the stroke that he painted on her face each birthday, she gets on the trace to find the ideal lover: the one that will be at the same time a sublime lover and a great calligrapher that will paint her body. But the story of the film 
is the less important thing, because the cinematographic language appears here like another way of writing, another way of speech that does not subjugate to the logic of an alphabetic text, but transform the character into an image: there are not just words that tell a story, but images that make sense in the context of a scene. 
Acta Poetica $28(1-2)$

PRIMAVERA-OTOÑO

2007

Sara Sutton

Universidad Iberoamericana

\section{Narrar la imagen.}

The Pillow Book

Aparece la piel como hoja de escritura: desde su delgadez se extiende en polisemias que se refugian en la tinta desparramada sutilmente sobre su tibia superficie. Pergamino que no promete más que su textura y que pide ser nombrado, ya no por una palabra, sino por la caricia de un pincel humedecido, prolongación de una yema rugosa que se revela en un laberinto indescifrable de huellas dactilares: laberinto de roces, de experiencias táctiles, de altiplanos rocosos erosionados por la humedad de otra piel exaltada y dispuesta para ser trazada. Mas el pergamino es ya en sí una escritura, pues constituye una superficie orgánica, marcada por los pliegues y rugosidades de su ser viviente. Su superficie es también todo su ser, detrás de ésta no hay más nada.

El libro de la almohada, de Sei Shonagon, escrito en el siglo $\mathrm{x},{ }^{1}$ es el texto que inspira a Peter Greenaway para filmar The Pillow Book. Sei Shonagon, una dama de la corte de la emperatriz de aquel tiempo, escribía en este diario sobre los deleites de la escritura. Es un diario, pero uno muy peculiar, pues éste

${ }^{1}$ El libro de la almohada, Madrid, Alianza, 2004. 
no constituye el relato de una vida que cobra sentido en la coherencia de una historia. Quizás no podamos concebirlo como un libro, ya que sus páginas no encuentran un hilo temporal que les dé continuidad, más bien, se encuentran fragmentadas por un conjunto de listados que apelan a los sentidos. Como la lista de "Cosas que hacen latir de prisa el corazón" a la que pertenece "advertir que un elegante espejo chino está un poco empañado"; o esa otra lista de "Cosas que pierden al estar pintadas", como serían los "claveles, las flores de cerezo, las rosas amarillas". Las cosas mentadas en estas listas cobran otro significado al ser tocadas por la sencillez del lenguaje escrito: un contenedor de hielo o un niño comiendo fresas, se convierten en trazo fino, en una imagen que le habla al cuerpo.

Nagiko, ferviente lectora del diario de Sei Shonagon e hija de un escritor y calígrafo, encuentra en la escritura algo más que un recurso literario. Marcada por el trazo que su amado padre pintaba sobre su rostro cada cumpleaños, se aboca a buscar, desde la muerte de éste, al hombre ideal: aquél que será un sublime amante y a la vez un excelso calígrafo que entinte su piel. Así, la escritura aparece como algo más que un crisol de significados. "No se trata de garabatear, sino de escribir", le dice desairada Nagiko a Jerome, quien se convertiría en su amante más amado. En su primer encuentro, Jerome —un traductor que mantenía una relación erótica con quien no sólo fue editor, sino también extorsionador sexual del padre de Nagiko- no logró plasmar sobre el cuerpo de ésta un trazo bello: no es sólo lo que se escribe, ni cómo se escribe, sino también cómo se traza: el texto se dibuja, ya que es también una imagen.

\section{La imagen, un tiempo pictórico}

¿Y desde dónde pensar la narración cinematográfica? Aquella escritura sensual de El libro de la almohada se dice diferente 
desde la mirada lúdica de la lente. No son sólo las escenas, sino la edición que las conjuga y la selección heterogénea de la música que las acompaña lo que descentra la mirada del espectador. Aquí, el lenguaje cinematográfico constituye otra forma de escriturar, otro modo de decir que no se subyuga a la lógica de un texto alfabético, sino que transforma la letra en imagen: no son sólo palabras que narran una historia, sino imágenes que cobran sentido en el entretejido de una escena.

Greenaway desprecia la función que ha tenido el cine hollywoodense al crear historias empalagosas y convencionales que exaltan la susceptibilidad del espectador, dejando intacta su ideología y sus convicciones o, más aún, sustentándolas y aplaudiéndolas. Nos dice Greenaway, en voz de Veron y Marguerite Gras en una bella introducción a un texto de entrevistas con el cineasta: "el arte no debiera alimentar los deseos humanos con sentimentalistas e ilusorios 'happy endings' o con trágicos o heroicos finales tan autocomplacientes, consoladores, y productores de dinero, como lo hace el cine hollywoodense". ${ }^{2}$ El cine comercial, nos dice, "tiende a desodorizar, romantizar y sentimentalizar". ${ }^{3}$ Podemos decir también, inspirados en Roland Barthes, que el cine "emocional y sentimentalista" pretende incitar una "tormenta visceral" que tiene por efecto obligar a la risa o al dolor a adoptar formas métricas simples, de manera que la pasión también se convierta en una mercancía como las otras, un objeto de comercio, insertada en un sistema numérico de intercambio: doy mi dinero [al cine], y como devolución exijo una pasión bien visible, casi computable (...). De cumplirse tal, entonces me sentiré felizmente

\footnotetext{
2 “[...] art shouldn't feed human wishful thinking with sentimental, delusional happy ending or tragical, heroical closures so self-serving, consoling, and Money producing as does the Hollywood cinema". Marguerite Gras, et al. (ed.), Peter Greenaway. Interviews, USA, University Press of Mississippi, 2000, p. IX.

3 "Most mainstream cinema tends to glamorize, deodorize, romanticize, and sentimentalize". Entrevista con Marcia Pally, "Cinema as the Total Art Form: An Interview with Peter Greenaway", en Ibid., p. 111.
} 
satisfecho "por haber colocado mi dinero en un talento que no lo dilapida, sino que me lo devuelve centuplicado bajo la forma de llantos y sudores verdaderos". ${ }^{4}$

Compartimos con Magali Arriola que el cine de Greenaway "combate el voyerismo implícito en el realismo cinematográfico", juego que consiste en mirar la vida ajena desde el cómodo aposento de una butaca, donde el espectador, en la obscuridad, permanece de cierta forma invisible ante la mirada del otro. "La posición fría y distante que nuestro director adopta frente a sus cintas hace de éstas dramas crudos y violentos"; sin embargo, al tomar tal distanciamiento - a diferencia del realismo cinematográfico - nos hace testigos de un acto de canibalismo al mismo tiempo que proscribe la implicación sentimental. El director de El bebé de Macon o de El cocinero, el ladrón, su esposa y su amante, busca perpetrar la distancia que nos separa de la imagen - tal y como sucede en la pintura- propiciando, frente a una imagen inquietante y a su vez estética, una "mirada corporal" y reflexiva más que convencional y sentimentalista. ${ }^{5}$

Greenaway padece de una especie de urticaria tanto frente a la interpretación psicológica del arte, como ante el cine hollywoodense que se reduce a narrar una historia: los llamados "telling-story" films. El cineasta evita por todos los medios el psicodrama y asevera que la vida, en su transcurrir más inmediato, jamás puede tener un final, pues la narrativa histórica — desde el presente mismo- no existe, sino que sólo puede ser inventada por un historiador. ${ }^{6}$ El director inglés, atravesado por su incursión en la pintura, intenta reivindicar el lenguaje particular del cine, desde su singular técnica. El cine - considera - no debe reducirse a un medio para narrar historias,

\footnotetext{
${ }^{4}$ Mitologías, México, Siglo XXI, 2002, pp. 110-111.

5 "Cine y pintura, ubicuidades y artificios", en Magali Arriola (ed.), Cine y pintura, ubicuidades y artificios, México, INBA, 1997, p. 19.

${ }^{6}$ Marguerite Gras, et al. (ed.), op. cit., p. IX.
} 
una especie de versión ilustrada y sonora de una novela. Esto significaría someter su lenguaje imaginario —en el sentido de imagen - al lenguaje narrativo de la literatura. El séptimo arte, siendo un medio que puede combinar libremente distintas técnicas, debiese ser desde allí otra propuesta discursiva: hacer de la imagen, discurso, y del texto, pretexto. Decir con la imagen y pintar con el texto.

\section{La estructura, un artificio sin símbolo}

El juego que hace Greenaway con las imágenes sirviéndose de las nuevas tecnologías multimedia, no sólo abre un abanico de posibilidades para repensar la imagen y, en particular, el cine, sino también la realidad. El tiempo que deja de ser lineal configura el presente como una serie de imágenes entrelazadas que trastoca el sentido de la narración y presenta los elementos, ya no como cosas que cobran sentido en una trama temporal, sino en un entramado de imágenes: el cuerpo-papel, el pincelamante, la escritura-danza, el trazo-soplo, la caligrafía-caricia.

Greenaway apuesta por un tiempo que se despliega en la sobreposición de imágenes que distorsionan la geometría del espacio. El cuadro escénico aparece como una obra pictórica que cobra un sentido que se agota en la escena misma. Desde aquí, el horizonte se encuentra en el presente inmediato de la imagen, como un entretejido de elementos pictóricos y no como un entrelazado de tiempos subsecuentes. Desde este acercamiento a la imagen fílmica, el texto también se revela como imagen y no sólo como continente simbólico: la escritura aparece como papel tapiz, como manta de seda que deja traslucir un cuerpo que habla.

La riqueza de la propuesta cinematográfica de Greenaway yace en la posibilidad de leer artificiosamente el presente como

cuerpo: la fragmentación e incoherencia del presente que no 
puede ser inscrita —en la inmediatez - dentro de una historia en el tiempo, sino como un presente-collage, un presente-puesta en escena; como una combinación de elementos que estéticamente convergen en una imagen. Esta escena corresponde a una lógica que no tiene que ver con el tiempo narrativo, sino con un sistema artificial de signos, con un código arbitrario de ordenamiento. Como, por ejemplo, la organización de The Pillow Book en capítulos que responden a un conjunto arbitrario de trece libros inscritos en cuerpos desnudos. De este modo, el instante aparece como una convergencia no fortuita pero artificial que se escribe ya no en una historia sino en una escena. Nos dice Greenaway, "si no tienes una historia que contar, entonces debes contar con otra lógica para organizar el material. De allí que haya buscado estructuras universales como el alfabeto. $\mathrm{O}$ ecuaciones matemáticas o tal vez series de números. Y —notemos la aclaración — no debiesen ser tomadas en serio, sino entenderlas como un delicado juego, como un crucigrama". ${ }^{7}$ Más adelante, nos confiesa: "Con cada cinta, invito a la gente a mi mesa y preparo la comida". 8

Al crear un orden artificial, invita al ojo a mirar desde otro lugar: no es ya una mirada detectivesca que intenta descubrir el sentido que se oculta tras las señas de una imagen para construir un relato coherente, sino un ojo como superficie permeable, que se deja acariciar por una imagen que lo desenfoca, y en la borrosidad del descentramiento, aparece otro decir configurado, quizás, en una palabra ornamental.

La preocupación de Greenaway por hacer evidente en sus cintas el artificio de toda producción cinematográfica, se asemeja, de algún modo, a la intención de Michel Foucault, en Las palabras y las cosas, por mostrar que no sólo la forma en que percibimos las cosas que configuran la realidad constituye una

\footnotetext{
${ }^{7}$ Hartum Buchholz, et al., "Two Things That Count: Sex and Death", en Ibid., p. 54.

8 "With each film, I invite people to my table and I make the meal".
} 
construcción performativa, sino que el mismo sistema que articula dichas cosas, la misma estructura taxonómica que ordena nuestro mundo, es producto de la más arbitraria invención; como, por ejemplo, la enciclopedia china del texto de Borges en la que los animales están clasificados de la siguiente manera: “a) pertenecientes al Emperador, b) embalsamados, c) amaestrados, (...) g) perros sueltos, h) incluidos en esta clasificación, i) que se agitan como locos, j) innumerables, k) dibujados con un pincel finísimo de pelo de camello, 1) etcétera, m) que acaban de romper el jarrón, n) que de lejos parecen moscas". ${ }^{9}$ Foucault nos muestra, en este estupendo texto, cómo la enciclopedia china de Borges pone en crisis el espacio mismo que debiese contener las relaciones lógicas entre las cosas que habitan el mundo; no sólo son las cosas las que son sacudidas, sino la misma lógica de su ordenamiento. Y lo más interesante es que esta revelación del desorden que se esconde en toda taxonomía, nos dice Foucault, "hace centellear los fragmentos de un gran número de posibles órdenes en la dimensión, sin ley ni geometría, de lo heteróclito". ${ }^{10}$

\section{La caligrafía, una imagen trazada}

En The Pillow Book, los recuadros que aparecen y desaparecen lúdicamente, sobreponiéndose al encuadre principal, pueden ser leídos como una especie de dislexia cinematográfica. Dislexia: rebelión contra la sintaxis, irreverencia frente a las estructuras lingüísticas que predeterminan el trazo. Así, la distorsión de la simetría del cuadro fílmico por la irrupción de otras imágenes, se rebelan ante la cuadratura rígida del formato cinematográfico, multiplicando las posibilidades de lectura.

\footnotetext{
${ }^{9}$ Las palabras y las cosas, México, Siglo XXI, 2005, p. 1.

${ }^{10}$ Ibid., p. 3.
} 
Desde este lugar podemos también pensar la escritura políglota que se inscribe sobre los cuerpos desnudos. Nagiko le pide a Jerome, su amante, que aprenda nuevas lenguas con el fin de inscribirlas sobre su cuerpo. Esta multiplicidad de lenguas puede ser leída aquí como un intento por descentrar la lengua vernácula y hacer estallar la lógica del lenguaje. Así, esta diversidad adquiere una nueva función: ya no consiste sólo en la posibilidad de extender la comunicación a lo largo del mundo - para alcanzar el estatuto de "literatura universal"- - sino para, por ejemplo, quebrar el sentido unívoco y la interpretación etimológica, al jugar con lo que podría significar una palabra en otra lengua, guiado sólo por un principio de sonoridad. Esto provocaría la eclosión de nuevos sentidos al jugar con la forma de las palabras, las cuales dicen otra cosa al ser leídas desde una lógica sonora y ya no semántica. De esta manera, la comunicación se transforma en formas lúdicas que se ríen estéticamente del lazo tiránico entre significado y significante.

Es interesante hacer notar que la escritura pintada sobre los cuerpos - después de ser transcrita por los escribas- está destinada a desvanecerse en los labios húmedos del editor, exaltados por la concupiscencia de los cuerpos pintados. Podemos decir que ésta es una escritura que no permanece, que no es ya un archivo: la tinta que se dibuja sobre el cuerpo, ese líquido espeso acogido por la superficie aterciopelada de la piel, se escurrirá por la boca que anhela, por el abrazo desenfrenado de un cuerpo humedecido.

No es casual que para realizar esta cinta, Greenaway haya elegido la escritura japonesa, pues ésta no sólo combina cotidianamente tres idiomas —el kanji, el hiragama y el katakana- sino que el kanji constituye un lenguaje jeroglífico. Y el jeroglífico es la figura por antonomasia que es texto e imagen a la vez. Más aún, los caracteres kanji eran, en un principio, ideogramas. La caligrafía china tiene más de dos mil años y, 
según la tradición, el inventor de esta escritura fue inspirado por las huellas que dejaban los animales sobre la arena o el lodo. Si nos atrevemos a jugar de forma irreverente con esta idea, podemos decir que la caligrafía aparece entonces como una escritura inspirada por otra escritura: la huella. La huella no como presencia o representación de las cosas, ni tampoco como la presencia de la ausencia, sino como el trazo que las cosas dejan a su paso. Enfaticemos, no su rastro, sino su trazo.

A diferencia del mundo occidental en que estamos acostumbrados a separar la imagen del texto, en la escritura oriental, el texto es indisociable de la imagen, ya que no constituye, como en nuestra escritura alfabética, un conjunto de fonemas que, por sí mismos, no tienen significado alguno. Para que cobre sentido la escritura fonética, es necesario realizar un proceso de síntesis en que la conexión de las distintas letras que forman una palabra, puedan ser leídas como una representación. Por el contrario, en el lenguaje jeroglífico, el sentido aparece de un solo golpe, pues los caracteres son en sí imágenes. Por ende, el calígrafo oriental no sólo es un escriba, sino también un pintor. Greenaway nos revela que la caligrafía está hecha con el cuerpo —o más aún, que es cuerpo. El calígrafo preserva una íntima relación con su trazo a través del cerebro, el hombro, el brazo, la mano, la pluma y el papel. ${ }^{11}$ En este sentido, la escritura manuscrita puede ser pensada como una "escritura corporal", en donde el cuerpo es, a su vez, un libro, y el libro, un cuerpo; sin embargo, nuestro cineasta nos aclara agudamente: "un libro puede ser una miríada de cosas más que sólo una narración". ${ }^{12}$

Así, en The Pillow Book, el cuerpo no es sólo una superficie de escritura sino que, tanto los cuadros escénicos como la escritura misma, aparecen, a su vez, como un cuerpo erótico

${ }^{11}$ Lawrence Chua, "Peter Greenaway: An Interview”, en Ibid., p. 180.

12 "The body is a book, the book is a body, but a book can be about a myriad of things other than narration". Ibid., p. 177. 
y estético que hacen de la técnica, discurso, multiplicando las posibilidades de lectura. Concebir el cuerpo como pergamino, el tiempo como imagen y la escritura como trazo, quizás, abra la posibilidad de pensar en una erótica de la escritura, una política del tiempo y una ética del cuerpo, inscritas, todas éstas, en un espacio artefactual, en el cual la actualidad, como nos dice Derrida $^{13}$ — debido, entre otras cosas, a las nuevas teletecnologías—, no puede ser ya pensada deslindada del artificio.

13 Jacques Derrida, Ecografías de la televisión, Buenos Aires, Eudeba, 1998. 